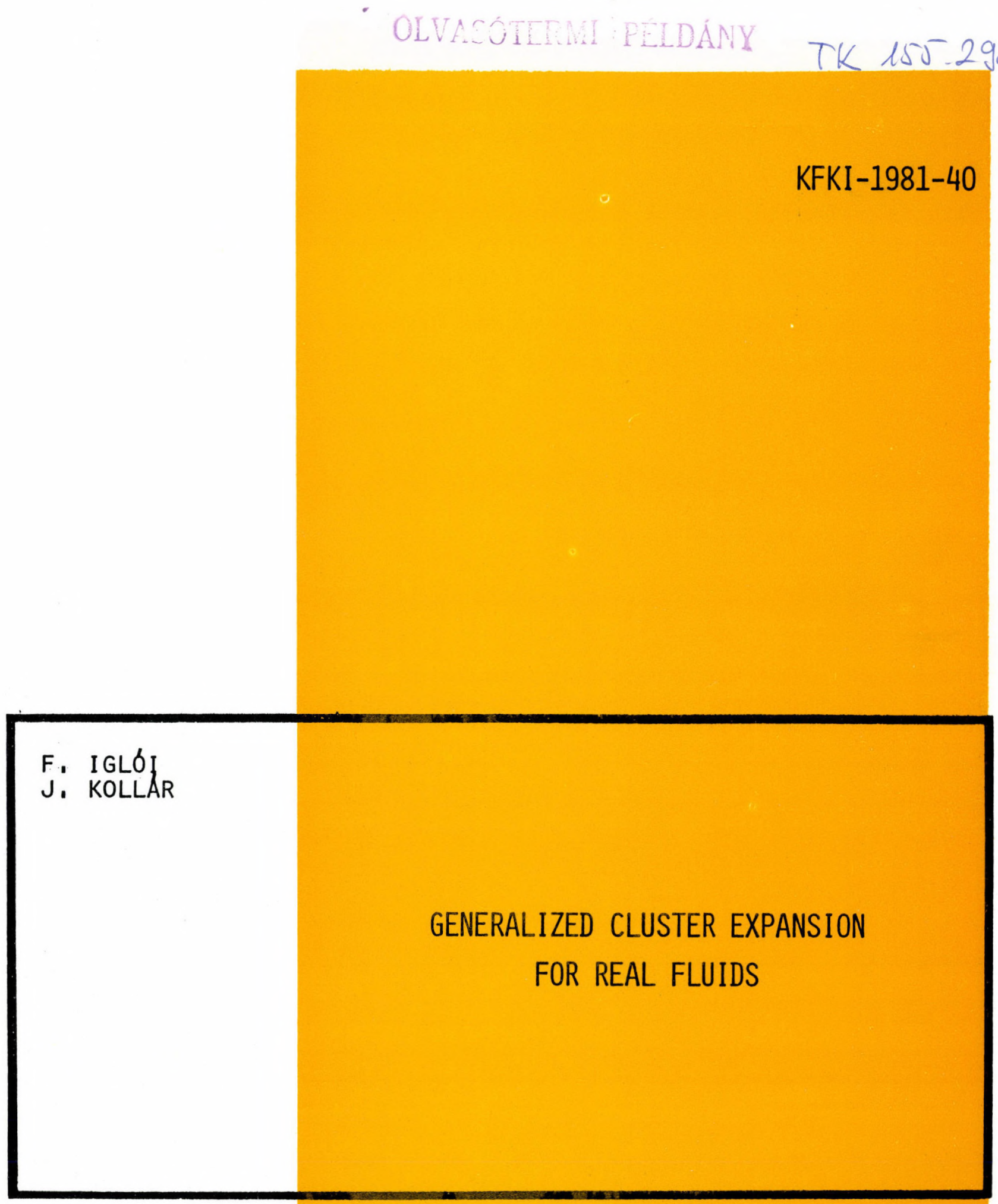

Hungarian Academy of Sciences CENTRAL RESEARCH INSTITUTE FOR PHYSICS 
KFKI-1981-40

\section{GENERALIZED CLUSTER EXPANSION FOR REAL FLUIDS}

$$
\text { F. Iglói and J. Kollár }
$$

Central Research Institute for Physics

H-1525 Budapest 114, P.O.B. 49, Hungary 


\section{ABSTRACT}

The equation of state and the pair correlation function of a real fluid is expressed in terms of the equation of state and distribution functions of a reference system. The derived general expression makes possible to obtain power series for the equation of state both in powers of a "softness" parameter $\mathbf{E}$ measuring the "amplitude" of the Boltzmann-factor difference, or in powers of a formal parameter $\lambda$ measuring the "amplitude" of the potential difference (high tempe: sture expansion).

\section{АННОТАЦИЯ}

Уравнение состояния і парная корреляционная Функция реальной жидкости определяются с помощью уравнеңія состояния и корреляционных функций системы, выбранной в качестве референции. Полученное обцее выражение позволяет выразить уравнение ссстояния в видє степенного ряда как по "параметру мягкости" छ, измеряющему "амглитуду" разности больцмановских факторов, так и по параметру $\lambda$, измеряюцему "амплитуду" разности потенциалов (высокотемпературное разложение).

\section{KIVONAT}

Egy reális folyadék állapotegyenletét és párkorrelációs függvényét kifejeztük egy referencia-rendszer állapotegyenlete és eloszlásfüggvényei segitségével. A levezetett általános kifejezésbôl az állapotegyenlet elôállitható mind egy $\xi$ "lágysági paraméter" (amely a Boltzmann-faktorok "amplitudóját" méri) hatványai szerint haladó, mind egy formális $\lambda$ paraméter (amely a potenciálkülönbség "amplitudóját" méri) hatványai szerint haladó hatványsor alakjában (ez utóbbi a magas hốmérsékleti sorfejtés). 
Recently a new perturbational method has been developed for the description of the equation of state and the pair correlation function for classical fluids ${ }^{1}$. The method was successfully applied for a hard sphere reference system ${ }^{2}$. This method contains an approximation concerning the calculation of certain cluster integrals. In this paper we derive general expressions for the equation of state and the pair correlation function for real fluids using the equation of state and distribution functions of a reference system in terms of diagrammatic expansion technique. We will show the connection between these generally derived expressions and those obtained in Ref. 1. We use the diagrammatic expansion technique developed by Morita and Hiroike ${ }^{3}$ and others $\mathbf{s}^{4,5}$. The notations and definitions are the same as those in Ref.6.

Consider a homogeneous system with identical classical particles, where the interaction energy is the sum of pair interactions. Thus the grand partition function of the system can be written as

$$
\begin{aligned}
\equiv & =\sum_{N=0}^{\infty} \frac{1}{N !} \int \ldots \int \prod_{i=1}^{N} z\left(\underline{r}_{i}\right) \prod_{i<j}^{N} e\left(\underline{r}_{i j}\right) d \underline{r}_{1} \ldots d \underline{r}_{-N}= \\
& =\sum_{N=0}^{\infty} \frac{1}{N !} \int \ldots \int \prod_{i=1}^{N} z\left(\underline{r}_{i}\right) \sum \prod_{i<j}^{N} f\left(\underline{r}_{i j}\right) d \underline{r}_{1} \ldots d \underline{r}_{-N}
\end{aligned}
$$

where $\underline{r}_{i j}=\underline{r}_{i}-\underline{r}_{j}$, and $z\left(\underline{r}_{i}\right)=z$ stands for the activity, which does not depend on $\underline{r}_{i}$ for a uniform system. The Boltzmann-function and the Mayer-function are denoted by $e(r)$ and $f(x)$ respectively. The logarithm of $\equiv$ can easily be expressed 
in diagrammatic terms ${ }^{6}$ as

$$
\begin{array}{r}
\ell n \equiv=[\text { the sum of all distinct connected diagrams } \\
\text { consisting of black z-circles and f-bonds] }
\end{array}
$$

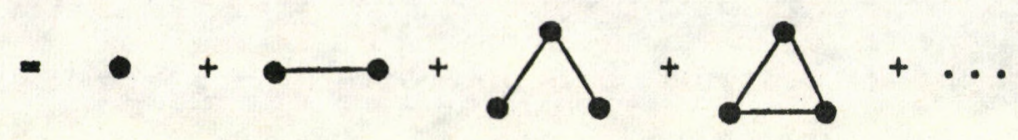

The n-particle density is defined as

$$
\rho_{n}\left(\underline{r}_{1} \ldots \underline{r}_{n}\right)=\frac{1}{\equiv} z\left(\underline{r}_{1}\right) \ldots z\left(\underline{r}_{n}\right) \frac{\delta(n) \equiv}{\delta z\left(\underline{r}_{1}\right) \ldots \delta z\left(\underline{r}_{n}\right)}
$$

where $\frac{\delta}{\delta z\left(\underline{x}_{1}\right)}$ denotes functional differentiation with respect to $z\left(\underline{r}_{i}\right)$. Applying the generalization of Lemma 2 . in Ref.6, the following result can be obtained:

$$
\begin{aligned}
p_{n}\left(\underline{x}_{1} \cdots \underline{x}_{n}\right)= & {[\text { the sum of all distinct connected diagrams con- }} \\
& \text { sisting of } n \text { white z-circles labelled } \underline{r}_{1} \cdots \underline{x}_{n} \\
& \text { black z-circles, e-bonds between each pair of } \\
& \text { white circles and some or no f-bonds between } \\
& \text { other circles] }
\end{aligned}
$$

Now let us introduce a reference system with the pair potential $u_{0}(x)$, the thermodynamic and structural properties of which are assumed to be known (hereafter the index "o" always refers to the reference system). Introducing the notation $\Delta f=e^{-\beta v(r)}-1$ (where $\left.v(x)=u(x)-u_{0}(x)\right)$ we can formally rewrite $f$ as

$$
f=f_{0}+e_{0} \Delta f
$$

Substituting this formula into Eq. 2, the following expression 
can be obtained for the logarithm of $\equiv$ ?

$$
\ln \equiv-\ln \equiv 0+\sum_{n=2}^{\infty} r_{n}
$$

where

$\Gamma_{n}=$ [the sum of all distinct connected diagrams consisting of at least $n$ black $z-c$ lrcles, $n$ of those are connected (at least) to another by an $e_{0} \Delta f$-bond, and some or no $f_{0}-$ bonds]

Comparing now the definitions of $\rho_{n}^{0}$ and $\Gamma_{n}$ we can see that the two sets of diagrams are similar to each other. In order to derive an exact relation between them, first we introduce the definition of an n-pont "skeleton diagram" $\sigma_{n, \mu}$, which consists of $n$ white z-circles labelled $\underline{r}_{1} \cdots \underline{r}_{n}$, each of them is connected (at least) to an other by $\Delta f$-bond, e.g.

$$
\begin{aligned}
& \sigma_{2,1}^{c}=\sigma_{12}^{0} \sigma_{3,1}^{c}=\rho_{0} \sigma_{3,2}^{c}=\sigma \\
& \sigma_{4,1}^{c} \ldots \sigma_{4,6}^{c}=?_{0}^{0} \cdots b_{0}^{\infty} \\
& \sigma_{4,1}^{d c}=\prod_{0}^{0}
\end{aligned}
$$

where the "c" and "dc" superscripts refer to the fact that the diagram is connected or disconnected, respectively. In terms of these skeleton diagrams the definition of $r_{n}$ can be rewritten a follow:

$$
\Gamma_{n}=\sum_{\mu} \frac{1}{s_{n, \mu}} \int \sigma_{n, \mu}\left(\underline{x}^{n}\right) \tilde{\rho}_{n, \mu}\left(\underline{x}^{n}\right) d \underline{x}^{n}
$$


where $s_{n, \mu} 1 s$ the symmetry number of the diagram which can be obtained from $\sigma_{n, \mu}$ by changing the white circles to black ones, and

$$
\begin{aligned}
& \tilde{\rho}_{n, \mu}=[\text { the sum of all distinct connected diagrams which } \\
& \text { consist of } n \text { white circles labelled } \underline{r}_{1} \ldots \underline{r}_{n} \text {, black } \\
& \text { z-circles, e -bonds between those white circles which } \\
& \text { are connected in the corresponding skeleton by } \Delta f-b o n d s, \\
& \text { and some or no fo-bonds] }
\end{aligned}
$$

In other words, $\Gamma_{n}$ can be obtained by attaching the white circles of $\sigma_{n, \mu}$ to the corresponding circles of $\tilde{\rho}_{n, \mu}$, integrate over the white circles and take into account only the topologically distinct diagrams. Since the number of the topologically equivalent diagrams is just given by $s_{n, \mu}$ defined above, Eq.7. follows directly from (6).

It is easy to show that if the skeleton diagram is connected, then

$$
\tilde{\rho}_{n, \mu}^{c}\left(\underline{r}^{n}\right)=\rho_{n}^{0}\left(\underline{r}^{n}\right)
$$

since the sum of all those diagrams of $\tilde{\rho}_{n, \mu}$ which differs from each other only in the number and positions of the $f_{0}$ -bonds between the white circles, results in a diagram which contains e -bonds between each pair of white circles, i.e. we get back the definition of $\rho_{n}^{0}$. If the skeleton is disconnected, the situation is more complicated. Assume now that $\sigma_{n, \mu}^{d c}$ splits into m subdiagrams (clusters) consisting of 
$n_{1}, n_{2} \ldots n_{m}$ white circles labelled $\underline{r}^{n_{1}}, \underline{r}^{n_{2}} \cdots \underline{r}^{n_{m}}$. If we carry out the summation of the diagrams in $\tilde{\rho}_{n, \mu}^{d c}$ similarly to that as in the case of $\tilde{\rho}_{n, \mu}^{c}$, we obtain $\tilde{\rho}_{n, \mu}^{d c}=$ [the sum of all distinct connected diagrams consisting of $n$ white $z$-circles labelled $\underline{r}_{1} \ldots \underline{x}_{n}$, black z-circles, o-bonds between each pair of white circles which are in the same cluster, and some or no $f_{0}$-bonds]

It is easy to show that the n-particle distribution function $\rho_{n}^{o}\left(\underline{r}^{n}\right)$ can be expressed in terms of the $\tilde{\rho}_{n, \mu}^{d c}$ functions which we call as "cluster distribution functions" in the following way. Assume that $n_{1} \leq n_{2} \leq \ldots \leq n_{m}$ and construct a set of different $v_{1}, v_{2} \ldots v_{M}=n$ numbers by grouping the clusters containing $n_{1}, n_{2} \cdots$ atoms in each possible way:

$$
\begin{aligned}
& v_{1}=n_{1} \\
& \dot{v}_{M}=n_{1}+n_{2}+\ldots n_{m}=n
\end{aligned}
$$

Then

$$
\begin{aligned}
& \rho_{v_{1}}^{0}=\tilde{\rho}_{v_{1}}^{0} \\
& \vdots \rho_{n}^{0}=\sum \tilde{\rho}_{v_{1}}^{0} \ldots \tilde{\rho}_{v_{2}}^{0} \ldots
\end{aligned}
$$

where the summation in the last equation extends, first, over all possible different combinations of the $v_{1}, v_{2} \ldots$ numbers for which $\sum v_{i}=n$, and second, for a given $\bar{v}_{1}, \bar{v}_{2} \ldots$ combination over all possible ways in which the coordinates $\underline{r}^{n_{1}}, \underline{r}^{n_{2}} \ldots$ can be devided into groups consisting of $\bar{v}_{1}, \bar{v}_{2} \ldots$ atoma. The eqs. (9) follow directly from the fact that $\tilde{\rho}_{v}^{\prime-s}$ 
contain only connected diagrams while in the definition of $\rho_{V}^{0,}-s$ there are disconnected diagrams as well. The set of diagrams which represents $\tilde{\rho}_{n}^{0}$ obviously contains all connected diagrams of $\rho_{n}^{0}\left(\tilde{\rho}_{n}^{0}\right.$ is the connected part of $\left.\rho_{n}^{0}\right)$, while the disconnected parts can be written as different products of lower order (connected) cluster distribution functions. Thus the sum in eq. (9) will always contain the $n-t h$ order cluster distribution function $\tilde{\rho}_{n}^{0}$ and the different products of lower order $\tilde{\rho}_{v}^{0,}-s$, and therefore

$$
\tilde{\rho}_{n}^{0}=\rho_{n}^{0}-\sum_{\nu_{1} \nu_{2}}^{\prime} \tilde{\rho}_{\nu_{1}} \cdots \tilde{\rho}_{\nu_{2}} \cdots
$$

where the prime denotes that $\tilde{\rho}_{n}^{0}$ is excluded from the summation. It is easy to show that $\tilde{\rho}_{n}^{0}$ defined in this way has the property, that it vanishes if the distance between the coordinates of one of the clusters (or any combinations of them) and the rest of the coordinates is large enough. We will show this by induction similarly to the case of the usual cluster functions ${ }^{7}$. Assume that this is true for $\tilde{\rho}_{\nu_{1}}^{0} \ldots \tilde{\rho}_{\nu_{K}}^{0}$ and consider $\tilde{\rho}_{\nu_{K+1}^{0}}^{0}=\tilde{\rho}_{\nu}^{0}$. If the coordinates $\underline{r}^{\nu}$ are devided into two groups, say $\underline{x}^{\bar{\nu}}$ and $\underline{\underline{x}}^{\nu-\bar{\nu}}$ and the distance between these groups is large, then

$$
\left.\rho_{\nu}^{0}\left(\underline{r}^{\nu}\right)=\rho \frac{0}{\nu}\left(\underline{r}^{\bar{\nu}}\right) \rho_{\nu-\bar{\nu}}^{0} \underline{\underline{r}}^{\nu-\bar{v}}\right)
$$

and from (9) we obtain

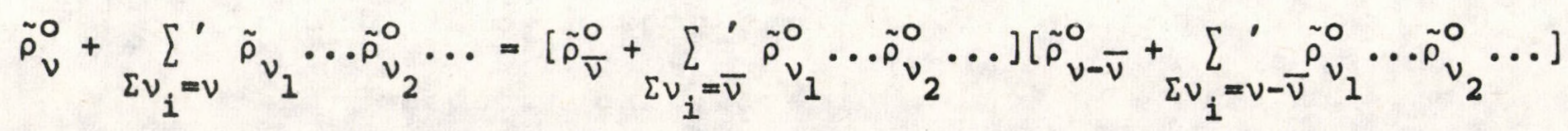


According to our assumption the sum in the left-hand side of Eq. (10) contains only those terms which correspond to the given separation of the coordinates, because $\tilde{\rho}_{\nu_{i}}^{0}\left(\underline{r}^{\nu_{i}}\right)=0$ if the coordinates $\underline{r}^{\nu_{i}}$ are taken both from $\underline{r}^{\bar{\nu}^{\prime}}$ s and from $\underline{r}^{\nu-\bar{\nu}}$ s. Therefore this sum is just equal to the right-hand side of Eq. (10), that is

$$
\tilde{\rho}_{v}^{0}=0
$$

This is also true for the lowest order non-trivial case, when

$$
\tilde{\rho}_{n_{1}+n_{2}}^{0}=\rho_{n_{1}+n_{2}}^{0}-\rho_{n_{1}}^{0} \rho_{n_{2}}^{0}
$$

This property assures the convergency of the expansion in eq. (7) in the thermodynamic limit, since in this case each term of the expansion is proportional to the volume $v$ of the system, as can be seen very easily. Namely, if once the coordinates of one of the particles have been fixed, the region of integration (where the integrand differs from zero) is reduced to a finite volume determined by the range of interaction of the potential difference $\nu(r)$ inside a given cluster (when $\Delta f \neq 0$ ) while the convergency of the integration over the relative coordinates of the particles in different clusters is assured by $\tilde{\rho}\left(\underline{r}^{n}\right)$ which tends to zero for large distances.

Introducing now the notations

$$
\begin{aligned}
& B V P_{n}^{c}=\sum_{\mu} \frac{1}{s_{n, \mu}} \int \sigma_{n, \mu}^{c}\left(\underline{x}^{n}\right) \rho_{n}^{o}\left(\underline{x}^{n}\right) d \underline{r}^{n} \\
& B V P_{n}^{d c}=\sum_{\mu} \frac{1}{s_{n, \mu}} \int \sigma_{n, \mu}^{d c}\left(\underline{x}^{n}\right) \tilde{\rho}_{n, \mu}^{o}\left(\underline{x}^{n}\right) d \underline{x}^{n}
\end{aligned}
$$


and from (5) and (7) we obtain

$$
\ln \equiv=\ln \equiv+\beta V \sum_{n}\left(P_{n}^{c}+P_{n}^{d c}\right)
$$

or the equation of state

$$
P=P_{0}+\sum_{n}\left(P_{n}^{c}+P_{n}^{d c}\right)
$$

Since the integrals in (11) are proportional to $v$, the quantities $P_{n}^{c}$ and $P_{n}^{d c}$ remains finite in the thermodynamic limit.

$$
\text { If the reference system is an ideal gas, then } \rho_{n}^{0}\left(\underline{x}^{n}\right)=z^{n}=\rho_{0}^{n}
$$
where $\rho_{0}$ stands for the density of the ideal gas reference system. It is easy to show from the definition (9) that in this case $\tilde{\rho}_{n, \mu}^{0}=0$ for all $n$ and $\mu$, and $B P_{0}=\rho_{0}$. Thus

$$
\begin{aligned}
& B P_{n}^{c}=\rho_{0}^{n} b_{n} \\
& B P_{n}^{d c}=0
\end{aligned}
$$

where $b_{n}^{\prime}$ are the reducible group integrals appearing in the usual activity expansion of the virial series and we obtain the well known result

$$
B P=\rho_{0}+\sum_{n=2}^{\infty} \rho_{0}^{n} b_{n}
$$

The particle density can be calculated in the following way ${ }^{1}$ :

$$
\rho=\rho_{0}\left[1+\left(\frac{\partial P_{0}}{\partial \rho_{0}}\right)^{-1} \sum_{n=2}^{\infty} \frac{\partial}{\partial \rho_{0}}\left(P_{n}^{C}+P_{n}^{d c}\right)\right]
$$

The basic equations of the method are (12) and (13), which differ from those given in Ref. I in the presence of the corrections $P_{n}^{d c}$. These corrections contain, even in lowest order 
two $\Delta f$-bonds. Introducing a "softness parameter" $\xi$, which is formally defined as

$$
\xi \overline{\Delta f}(r)=\Delta f(r)
$$

we can see that the contribution of the disconnected diagrams is of the order of $\xi^{2}$. Since the results for the hard sphere reference system ${ }^{2}$ show that in most of the cases the accuracy of the method is satisfactory already in first order, when only connected diagrams appear in the calculation, in applications the disconnected terms $P_{n}^{d c}$ are of little importance.

Furthermore, we mention that expanding $\Delta f$ in powers of the potential difference $v(r)$ and collecting the terms of the same order, Eqs. (12) and (13) allow us to calculate any higher order term in the high temperature expansion (or $\lambda$-expansion) as well (see e.g. in Ref.6.).

It is easy to calculate the pair correlation function $g_{2}(x)$ using Eq. (3) first order in $\xi$ in the same way as in Ref. 1.8

$$
\begin{aligned}
g_{2}\left(\underline{r}_{12}\right) & =g_{2}^{\circ}\left(\underline{r}_{12}\right) e_{0}^{-1}\left(\underline{r}_{12}\right) e\left(\underline{r}_{12}\right)+\xi 2 \rho \int g_{3}^{\circ}\left(\underline{r}_{1} \underline{r}_{2} \underline{r}_{3}\right) \overline{\Delta f}\left(\underline{r}_{12}\right) d \underline{r}_{3} \\
& -\xi \frac{\partial P_{2}^{c}}{\partial \rho}\left(\rho \frac{\partial P}{\partial \rho}\right)^{-1}\left[\rho^{2} g_{2}^{\circ}\left(\underline{r}_{12}\right)\right]^{\prime} \\
& +\xi \rho^{2} \int\left[g_{4}^{\circ}\left(\underline{r}_{1} \underline{r}_{2} \underline{r}_{3} \underline{r}_{4}\right)-g_{2}^{\circ}\left(\underline{r}_{1} \underline{r}_{2}\right) g_{2}^{\circ}\left(\underline{r}_{3} \underline{r}_{4}\right)\right] \overline{\Delta f}\left(\underline{r}_{34}\right) d \underline{r}_{3} d \underline{r}_{4}+o(\xi)^{2}
\end{aligned}
$$

The last term in the right-hand side of (14) is the first order correction to the Eq. (23) of Ref. 1. This pair correlation function satisfies the compressibilicy equation and goes to unity for large distances as well. 
To summarize we can say that we derived an exact expression for the equation of state ((12) and (13)) and the pair correlation function (Eq. (14)) of a real fluid using the equation of state and the distribution functions of a reference system and the $\Delta f(r)$ Mayer-function for the potential difference. From the general formulas one can derive power series for the equation of state both in powers of a softness parameter $\xi$ or in powers of a formal parameter $\lambda$ (high temperature expansion). 


\section{REFERENCES :}

1.) J. Kollár (to appear in Phys. Rev. A 1981. May)

2.) F. Igldi and J. Kollár (to appear in Phys. Rev. A 1981. May)

3.) T. Morita and K. Hiroike Prog. Theor Phys. 25, 537 (1961)

4.) C. De Dominicis J. Math. Phys. 3 , 983 (1962)

5.) G. Stell In "The Equilibrium Theory of Classical Fluids" (H.L. Frisch and J.L. Lebowitz, eds.), p. II-171. Benjamin, New York (1964)

6.) J.P. Hansen and I.R. MCDonald "Theory of Simple Liquids", Academic Press, London (1976)

7.) D. ter Haar "Elements of Statigtical Mechanics", Holt, Rinehart and Winston, New York (1960) 






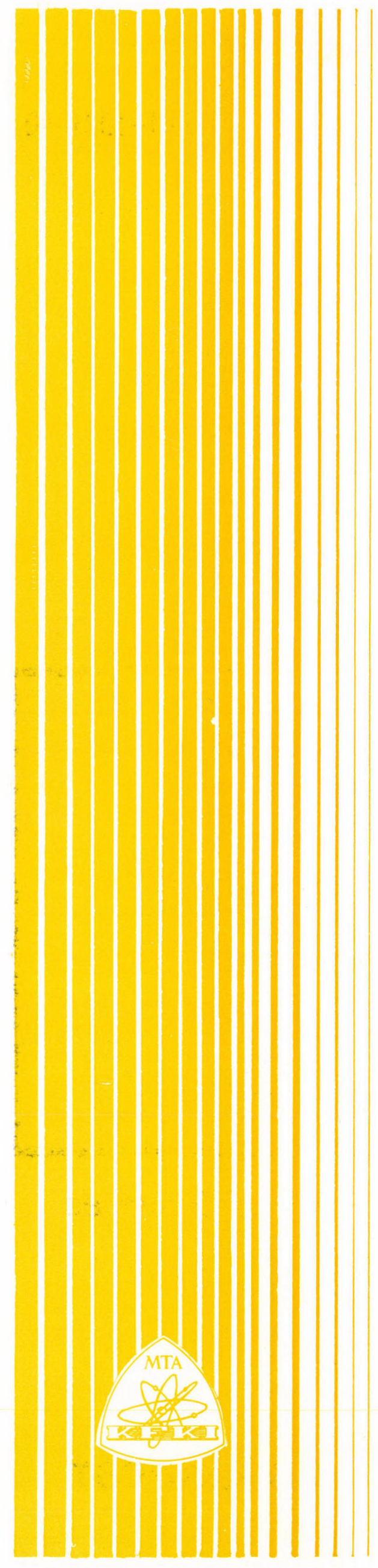

Kiadja a Központi Fizikai Kutató Intézet Felelós kiadó: Kroó Norbert

Szakmai lektor: Tüttō István Nyelvi lektor: Sólyom Jenố Példányszám: 500 Törzsszám: 81-322 Készült a KFKI sokszorositó üzemében Felelốs vezető: Nagy Károly Budapest, 1981. május hó 